\title{
Spontaneously resolved uterine prolapse in a neonate with spina bifida
}

\author{
Hacer Yapıcıoğlu Yıldızdaş ${ }^{1}$, Ümit Ece ${ }^{2}$, Gülseren Bilen Yurdakul², Eda Kolağasıgil ${ }^{3}$ \\ ${ }^{1}$ Division of Neonatology, Department of Pediatrics, Çukurova University Faculty of Medicine; ${ }^{2}$ Newborn \\ Intensive Care Unit and ${ }^{3}$ Gynecology and Obstetric Clinic, Private Adana Algomed Hospital, Adana, Turkey. \\ E-mail: hyapicioglu@cu.edu.tr \\ Received: 3rd July 2018, Revised: 14th September 2018, Accepted: 16th October 2018
}

SUMMARY: Yapıcıoğlu Yıldızdaş H, Ece Ü, Bilen Yurdakul G, Kolağasıgil E. Spontaneously resolved uterine prolapse in a neonate with spina bifida. Turk J Pediatr 2019; 61: 979-981.

Neonatal uterine prolapse is rare and mostly due to spina bifida. It is probably due to abnormal innervation of levator ani and subsequent atrophy of the muscle in patients with spina bifida.

Here we report a newborn patient with uterine prolapse after meningomyelocele operation. Foley catheter was used to manage uterine prolapse, however rectal prolapse occurred and catheter was pulled out. She was followed in an outpatient clinic without any management. She is now seven months old and had no uterine prolapse since the age of two months.

Key words: newborn, uterine prolapse, spina bifida.

Neonatal uterine prolapse is a rare condition. The first case with uterine prolapse was reported by Conovius ${ }^{1}$ in 1723 and to date most of the reported cases were associated with spina bifida. ${ }^{2}$ The main reason in spina bifida is impaired innervation of pelvic floor. Conservative management such as manual reduction or insertion of a Foley catheter to vagina or surgical management may be options in treatment.

Here we report a newborn baby with uterine prolapse after meningomyelocele operation and discuss the pathogenesis in spina bifida.

\section{Case Report}

The baby was admitted to the Newborn Intensive Care Unit after birth for meningomyelocele operation. She was the second child of non-consanguineous parents. She was delivered at 39 gestational weeks. Birth weight was 3,320 g (50-75 p), head circumference $35 \mathrm{~cm}(50 \mathrm{p})$ and length 49 $\mathrm{cm}$ (50 p). Apgar scores were 9 and 10 at 5 th and 10th minutes, respectively. She had a $5 \times 6 \mathrm{~cm}$ meningomyelocele located on the lumbosacral region, and bilateral equinovarus; hips were externally rotated and there was minimal movement in the lower extremities. She was operated on the 3rd day of life. She had no problems after the operation and was fed orally. Cranial ultrasound was normal. On day-6, she had uterine prolapse. Although digital reduction was successful, reprolapse occurred soon (Fig. 1). A 8-F Foley catheter was inserted via vagina after digital reduction

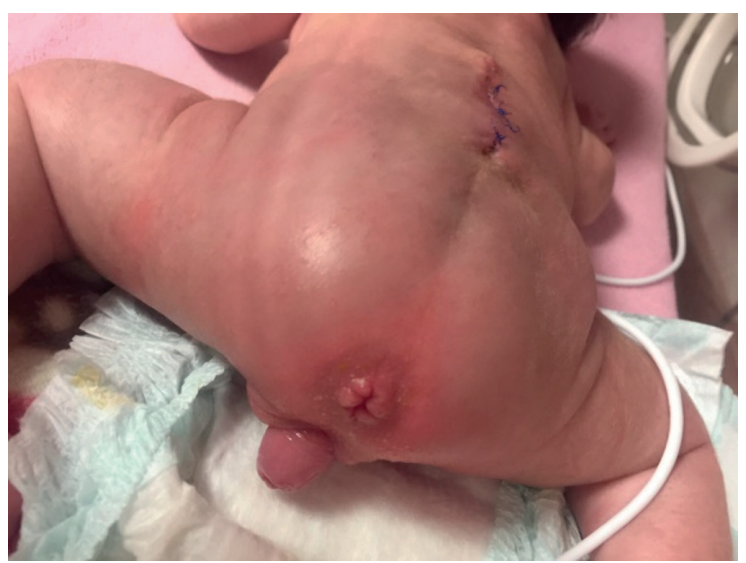

Fig. 1. Uterine prolapse after surgery for meningomyelocele. 
and the balloon was inflated, however she had rectal prolapse on the same day, she was restless and Foley catheter was removed. Uterus could not be visualized by abdominal and pelvic ultrasonography. On the other days, although easily manually reducted, she had reprolapse. Uterus was kept wet by wet gauze applied on it and manual reduction was taught to the mother. She was discharged on the 15th day of life. Uterine prolapse spontaneously resolved after two months of age. She is now 7 months old and she has no reprolapse (Fig. 2 ). Informed consent was gained from the parents.

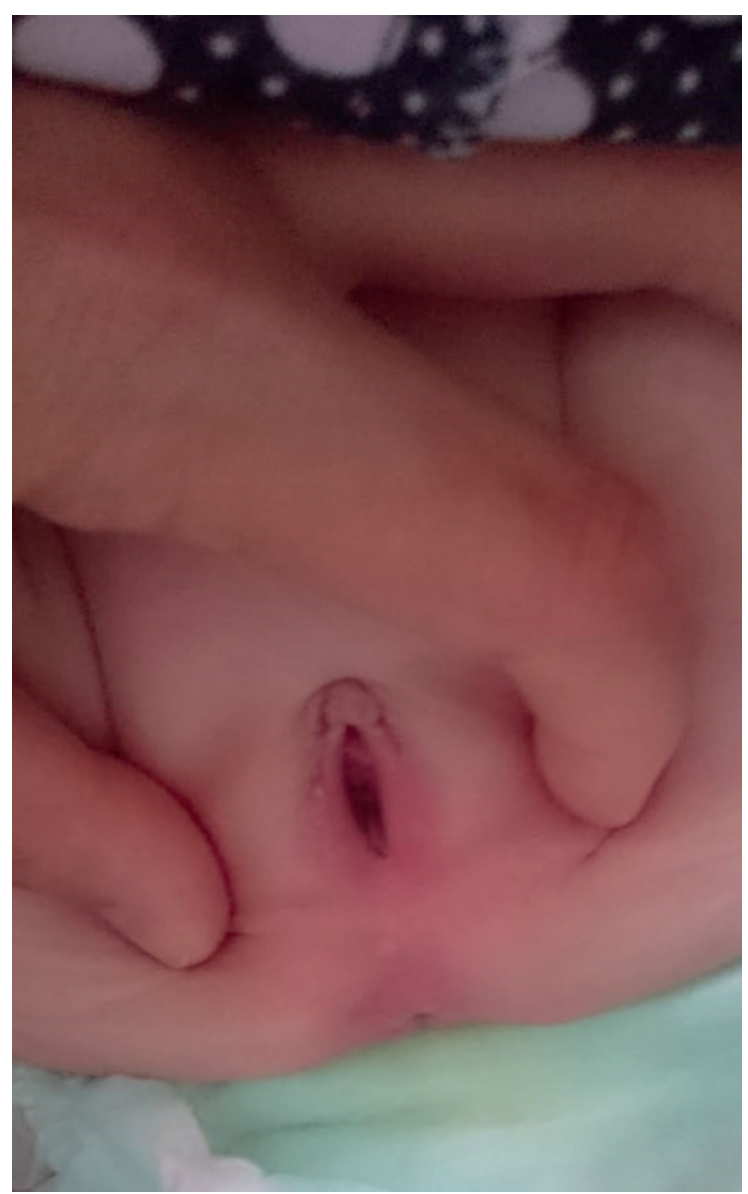

Fig. 2. Genital view of the same patient at seven months of age.

\section{Discussion}

Neonatal uterovaginal prolapse was first described by Conovius in $1723 .{ }^{1}$ Up to 2015 , 69 cases have been reported. ${ }^{2}$ Most of the cases are associated with spina bifida either occult or with meningomyelocele. In Henn et al.'s ${ }^{2}$ study, $77 \%$ of the cases were associated with spina bifida. Uterovaginal prolapse has been reported also with birth trauma, prolonged birth, breech presentation ${ }^{3}$, tetanus ${ }^{4}$ and following resection of sacrococcygeal teratome. ${ }^{5}$ Vaginal prolapse can even occur inutero. Cheng et al. $^{6}$ reported one case with vaginal prolapse diagnosed prenatally at 20 weeks of gestational weeks. There was no identified cause after birth and vagina was reducible by a Q-tip.

Although genital prolapse can be easily recognized, urethral prolapse, ureterocele, imperforate hymen, paraurethral cysts, vaginal polips, rhabdomyosarcoma should be kept in mind for differential diagnosis. Etiology in newborns with normal neurological findings has not been understood. In newborns with spina bifida, it is probably due to abnormal innervation of levator ani and subsequent atrophy of the muscle. Levator ani is the muscle in the pelvic floor which stabilizes the abdominal and pelvic organs. It constricts the lower part of the rectum and vagina. This muscle group is primarily innervated by a branch from the fourth sacral nerve. In the present case, uterine prolapse occurred after the surgery, it may be due to either innervation defect due to spina bifida or due to surgery itself. It was most likely to be due to surgery and after two months of recovery duration, prolapse was not present anymore.

Techniques such as purse-string vaginal suturing, labial suturing, cervical amputation, uterine ventrosuspension and sacrocolpopexy have been described to manage prolapse. ${ }^{3,5}$ Conservative managements by manual reduction, hypertonic saline packs, pessaries or use of Foley catheters may be other options..$^{7-9}$ However there is a high recurrence rate in newborns with spina bifida after simple reduction..$^{8,9}$ If there is recurrence or vaginal mucosal ulceration or hypertrophy, surgical intervention is indicated. Abdelsalam et al. ${ }^{7}$ reported a successful management of genital prolapse using Foley catheter in a newborn. Unfortunately it was disturbing and caused rectal prolapsus in our patient, so we pulled it back. Rectal prolapse is the extrusion of some or all of rectal mucosa through the external sphincter. It is rare in neonates. 
Rectal prolapse is mostly due to constipation in children. In El-Chammas et al's ${ }^{10}$ study, the most common association with rectal prolapse was constipation. Of 262 patients, there was an identified diagnosis in 194 patients, constipation in $52.1 \%$ of the patients, acute diarrhea in $12 \%$, imperforate anus in $8 \%$, rectal polyps in $6 \%$ and cystic fibrosis in $3.6 \%$. Out of the patients $5 \%$ had meningomyelocele. ${ }^{10}$ Increased intraabdominal pressure in constipation and acute diarrhea is the leading cause in rectal prolapse, however in the present patient probably innervation disorder of the pelvic floor and the increased effect of the inflated balloon of Foley catheter were the main reasons.

In conclusion, genital prolapse is rare and may be associated with meningomyelocele due to abnormal pelvic innervation. Simple digital reduction may not be successful and patients may need surgical intervention. However patients may be observed before a surgical management as prolapse may resolve spontaneously.

\section{REFERENCES}

1. Noyes IH. Uterine prolapse associated with spina bifida in the newborn, with report of a case. Am J Obstet Gynecol 1927; 13: 209-213.
2. Henn EW, Juul L, van Rensburg K. Pelvic organ prolapse in the neonate: report of two cases and review of the literature. Int Urogynecol J 2015; 26 : 613-615.

3. Loret de Mola JR, Carpenter SE. Management of genital prolapse in neonates and young women. Obstet Gynecol Surv 1996; 51: 253-260.

4. Akcakus M, Gunes T, Kurtoglu S, Cetin N, Pac A, Okur H. Neonatal uterine prolapse. Pediatr Int 2003; 45: 349-351.

5. Pirgon O, Atabek ME, Suleymanoglu S. Genital prolapse in a newborn following resection of sacrococcygeal teratome. J Pediatr Adolesc Gynecol 2009; 22: e96-e98.

6. Cheng PJ, Shaw SW, Cheuh HY, Soong YK. Prenatal diagnosis of fetal genital prolapse. Ultrasound Obstet Gynecol 2005; 26: 204-206.

7. Abdelsalam SEA, Desouki NM, Abd alaal NA. Use of Foley catheter management of neonatal genital prolapse: case report and review of the literature. J Pediatr Surg 2006; 41: 449-452.

8. Johnson A, Unger SW, Rodgers BM. Uterine prolapse in the neonate. J Pediatr Surg 1984; 19: 210-211.

9. Shuwarger D, Young RL. Management of neonatal genital prolapse: case reports and historic review. Obstet Gynecol 1985; 66 (Suppl 3): S61-S63.

10. El-Chammas KI, Rumman N, Goh VL, Quintero D, Goday PS. Rectal prolapse and cystic fibrosis. J Pediatr Gastroenterol Nutr 2015; 60: 110-112. 